\title{
Health Promotion and Care-Work Site
}

National Cancer Institute

\section{Source}

National Cancer Institute. Health Promotion and Care-Work Site. NCI Thesaurus. Code C18831.

Programs at the work site to promote health (e.g., anti-smoking). 